\title{
COMERCIALIZAÇÃO DE FRUTAS EXÓTICAS ${ }^{1}$
}

\author{
HÉLIO SATOSHI WATANABE² \& SABRINA LEITE DE OLIVEIRA ${ }^{3}$
}

RESUMO- Nas Centrais de Abastecimento - CEASAs, a fruta é considerada exótica quando comercializada em menor volume. Apesar do aumento significativo da demanda de algumas frutas exóticas nos últimos anos, o volume total ainda é pequeno em relação ao volume total das demais frutas. Em 2012, na Companhia de Entrepostos e Armazéns Gerais de São Paulo - CEAGESP, as frutas exóticas representaram 0,65\% do volume total de frutas comercializadas e 2,09\% do volume financeiro do setor de frutas. A oferta de algumas frutas exóticas na CEAGESP teve crescimentos surpreendentes nos últimos 5 anos, como foi o caso da lichia, romã, mangostão, pitaya, physalis e das frutas vermelhas- amora e framboesa. Por outro lado, carambola, abiu e umbu tiveram o volume comercializado diminuído nos últimos 3 anos.

Termos para indexação: CEAGESP, carambola, jabuticaba, lichia, romã

\section{EXOTIC FRUITS COMMERCE}

ABSTRACT-Small volume fruits are considered exotic at the fresh produce terminal markets - CEASAs of Brazil. The exotic fruits volume is growing, but its volume remains much smaller compared to other fruits. The exotic fruits were $0,65 \%$ of the total fruit volume and $2,09 \%$ of the value at 'Companhia de Entrepostos e Armazéns Gerais de São Paulo - CEAGESP' - Terminal market of São Paulo, in 2012. A large growth of some products in the last five years has been observed: litchee, pomegranate, mangosteen, physalis, berries - black berries and goose berries. Other fruits - starfruit, abiu and umbu has shown decreasing volume in the last three years.

Index terms: CEAGESP, starfruit, litchee, jabuticaba, pomegrante.

\section{INTRODUÇÃO}

Do ponto de vista biológico, frutas exóticas são todas aquelas que foram introduzidas de outros países, já alguns autores consideram como sendo frutas exóticas todas aquelas que apresentam o sabor diferenciado ou características diferenciadas que as distinguem dos demais no formato, cor e arquitetura da planta.

Normalmente, nos principais mercados atacadistas (CEASAs), além de suas características peculiares, são consideradas frutas exóticas aquelas que são comercializadas em menor volume.

No sistema PROHORT da Companhia Nacional de Abastecimento - CONAB, em seu relatório, é possível extrair a movimentação de volume e valor comercializado das principais frutas exóticas.

Na Seção de Economia e Desenvolvimento SEDES - da Companhia de Entrepostos e Armazéns Gerais de São Paulo - CEAGESP, através de seu Sistema de Informação e de Estatísticas de Mercado SIEM, é possível obter o volume, o valor e as origens dos principais produtos comercializados, dentre os quais as frutas exóticas.

Na CEAGESP, o setor de cotação realiza diariamente levantamento de preços dos principais produtos comercializados, porém daqueles produtos considerados sazonais ou exóticos muitos não são cotados por serem pouco expressivos em volume e/ou valor.

Os preços médios informados diariamente nos principais meios de comunicação dos produtos hortigranjeiros são oriundos de pesquisas realizadas pela CEAGESP e que são utilizados por vários canais de comercialização.

$\mathrm{O}$ volume comercializado e o volume financeiro das frutas exótica comercializadas nas CEASAs decresceram no último ano, como mostra a Tabela 1.

Dos produtos comercializados pelos atacadistas, ao adentrarem na dependência da CEAGESP, obrigatoriamente, é necessário deixar a $2^{\mathrm{a}}$ via da nota fiscal, que é encaminhada para o setor de estatística para consolidação dos dados. Em 2012, o setor de frutas da CEAGESP consolidou 73 diferentes

${ }^{1}$ (Trabalho 443-13). Recebido em: 20-09-2013. Aceito para publicação em: 15-12-2013. Palestra II Simpósio Internacional de Fruticultura- Frutas Exóticas, 21 a 25 de outubro de 2013. Jaboticabal-SP.

${ }^{2}$ Engenheiro. Agrônomo, CEAGESP. E-mail: hwatanabe@ceagesp.gov.br

${ }^{3}$ Engenheira Agrônoma, Mestra em Tecnologia Pós-Colheita, CEAGESP. E-mail: sloliveira@ceagesp.gov.br 
espécies, num total de $1.791 .678 \mathrm{t}$, sendo 11.722 t de frutas exóticas, representando $0,65 \%$ do total comercializado (SISTEMA DE INFORMAÇÃO E ESTATÍSTICA DE MERCADO, 2013). A carambola foi a $25^{\text {a }}$ fruta mais comercializada em 2012 na CEAGESP e, entre as frutas exóticas, foi a primeira do ranking (Tabela 2 ).

$\mathrm{O}$ volume financeiro total do setor de frutas da CEAGESP, em 2012, foi de R \$3.035.047.456,00, sendo R\$63.328.161,00 de frutas exóticas, representando 2,09\%. A jabuticaba foi responsável por $30,81 \%$ do volume financeiro das frutas exóticas (Tabela 3).

Evolução de entrada e preço médio das principais frutas exóticas comercializadas na CEAGESP

\section{Lichia}

O volume e o preço de comercialização da lichia, registrados em 2012 na CEAGESP, foram inferiores ao de 2011 (Figura 1).

Os meses de maior oferta de lichia na CEAGESP são dezembro e janeiro (Tabela 4), e os melhores preços são alcançados nos meses de outubro e novembro (Tabela 5).

\section{Romã}

O volume de comercialização da romã cresceu nos últimos anos, embora o valor de venda tenha diminuído em 2012 (Figura 3).

Os meses de maior oferta de romã na CEAGESP são novembro, dezembro e janeiro (Tabela 6), e os de melhores preços são agosto, setembro e outubro (Tabela 7).

\section{Rambutã}

A evolução do volume de rambutã comercializada na CEAGESP, entre os anos de 2007 e 2012, está apresentada na Tabela 8. Os meses de maior oferta são de abril a agosto (Tabela 9).

\section{Pitaya}

De 2007 a 2012 houve um aumento de mais de $250 \%$ no volume de comercialização de pitaya na CEAGESP (Tabela 12). Os meses de maior oferta são de dezembro a abril (Tabela 13).

\section{Amora}

O volume de comercialização da amora na CEAGESP, em 2012, foi o mais alto dos últimos 6 anos (Tabela 14). Os meses de melhor oferta são de setembro a janeiro (Tabela 15).

\section{Framboesa}

O preço por quilo da framboesa na CEAGESP aumentou nos últimos anos. Entre 2010 e 2011, houve um aumento de mais de $100 \%$ no volume de comercialização, embora tenha diminuído no último ano (Tabela 16). Os meses de maiores ofertas são janeiro, fevereiro, junho, julho, agosto, novembro e dezembro (Tabela 17). E os meses de melhor preço são de novembro a abril (Tabela 18).

\section{Physalis}

O volume de comercialização aumentou nos últimos 6 anos (Tabela 19). Os meses de maior oferta são de setembro a janeiro (Tabela 20).

\section{Carambola}

$\mathrm{O}$ volume de carambola comercializada na CEAGESP diminuiu nos últimos 2 ano, e,no mesmo período, o preço subiu 12\% (Figura 11). Os meses de maior oferta são de janeiro a agosto (Tabela 21), e os de melhores preços, de outubro a novembro (Tabela 22).

\section{Abiu}

$\mathrm{O}$ volume de abiu comercializado na CEAGESP teve uma queda em 2012 (Tabela 23). Os meses de maior oferta são de janeiro a maio e de julho a agosto (Tabela 24).

\section{Umbu}

Nos últimos 3 anos, o volume de umbu comercializado na CEAGESP diminuiu (Tabela 25). Os meses de maior oferta são janeiro, fevereiro e dezembro (Tabela 26). 


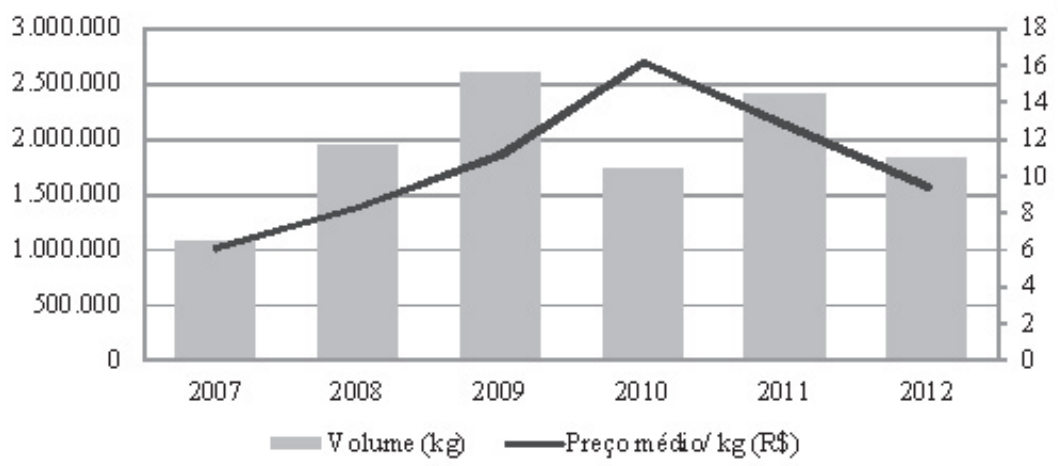

FIGURA 1- Evolução do volume em kg e do preço médio por kg da lichia comercializada na CEAGESP, entre 2007 e 2012. Fonte: SISTEMA DE INFORMAÇÃO E ESTATÍSTICA DE MERCADO, 2013.
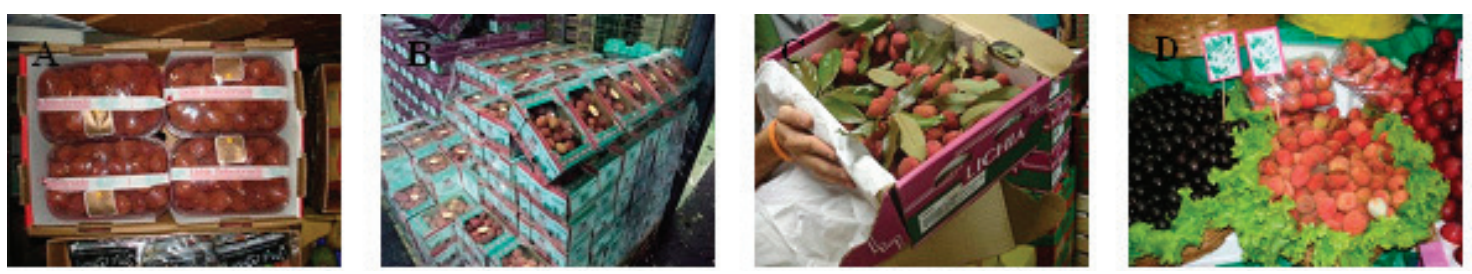

FIGURA 2- Venda de lichia: A - desidratada no varejo; B - in natura no varejo; C - a granel no atacado, e D - a granel no varejo.

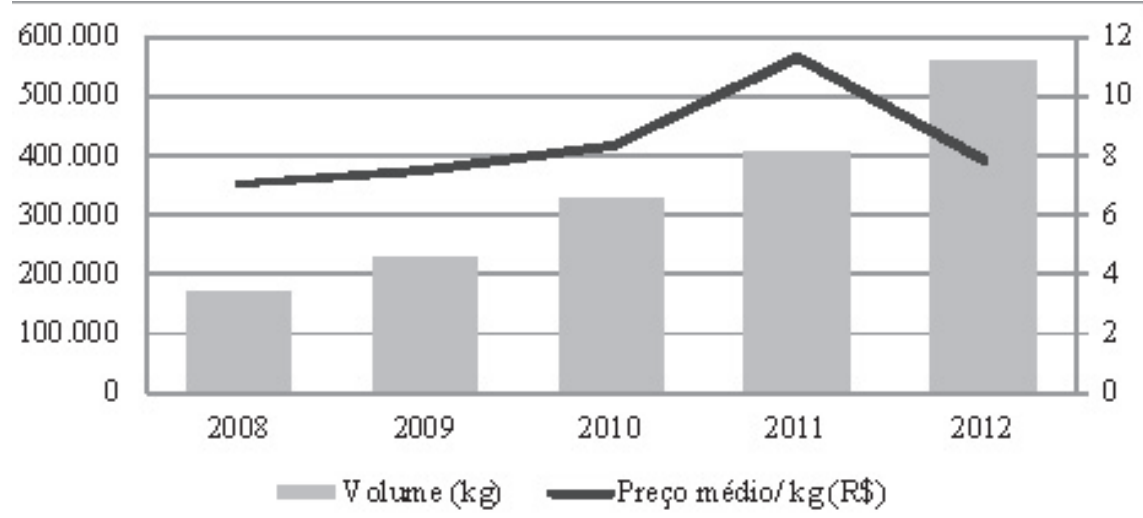

FIGURA 3- Evolução do volume em quilos e do preço médio por quilo da romã comercializada na CEAGESP, entre 2008 e 2012. Fonte: SISTEMA DE INFORMAÇÃO E ESTATÍSTICA DE MERCADO, 2013.
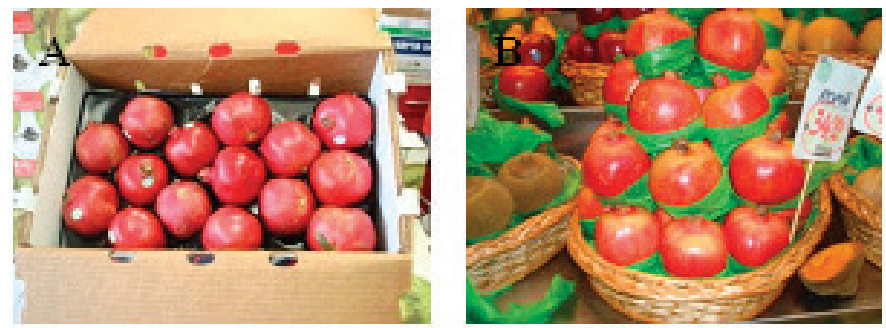

FIGURA 4- Venda de romã: A - atacado, e B - varejo. 

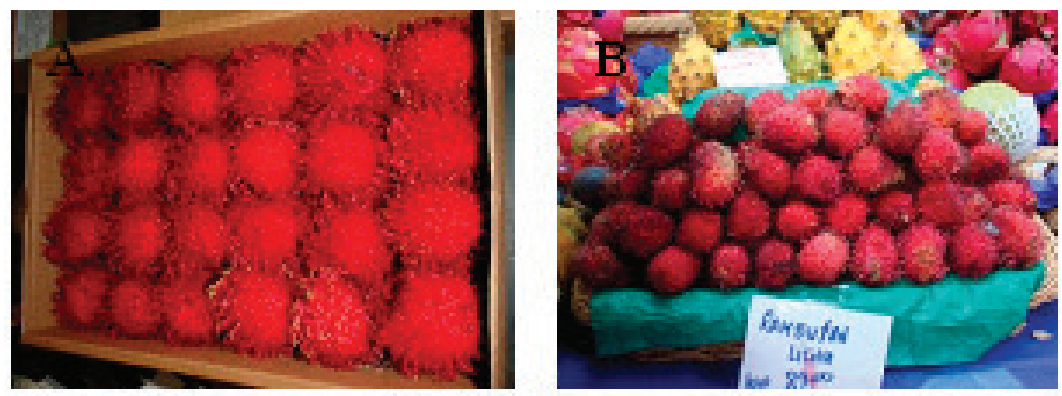

FIGURA 5- Venda de rambutã: A - atacado, e B - varejo.
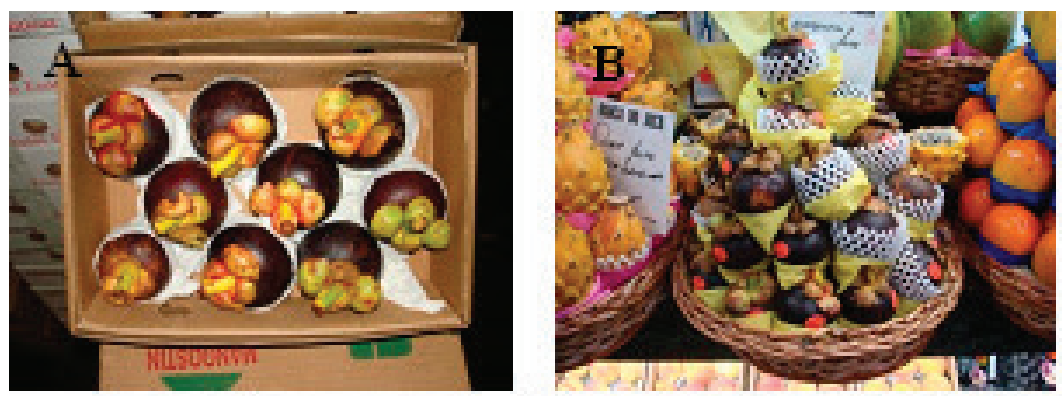

FIGURA 6-Venda de mangostão: A - atacado, e B - varejo.
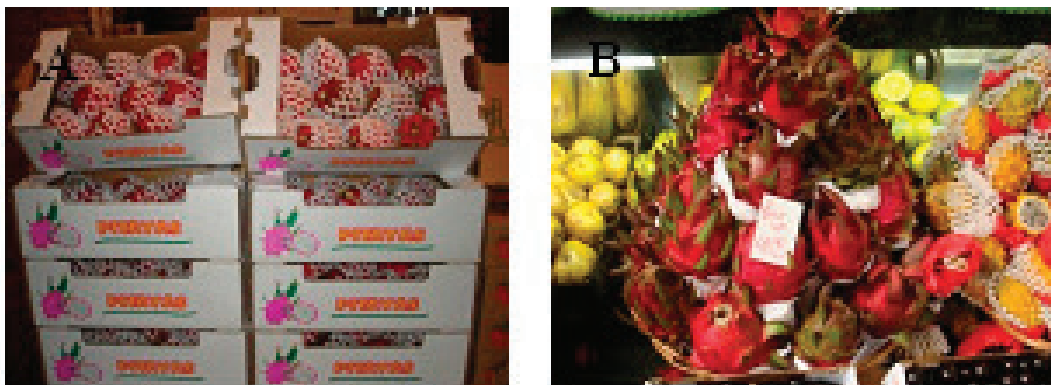

FIGURA 7- Venda de pitaya: A - atacado, e B - varejo.
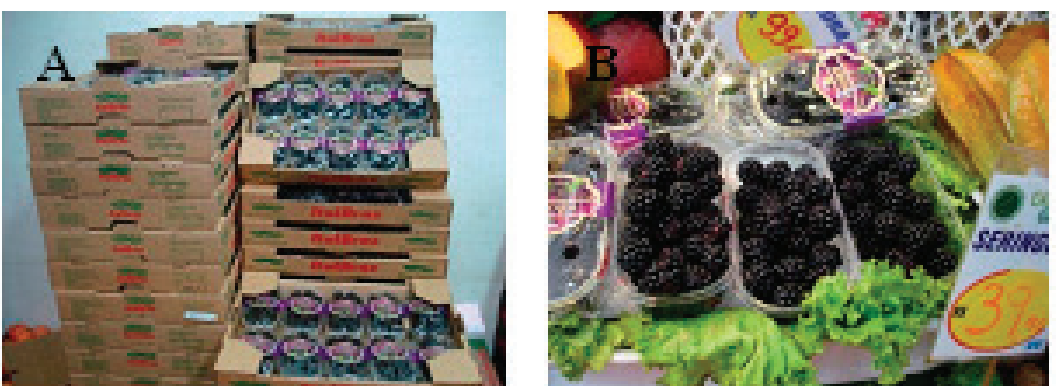

FIGURA 8 - Venda de amora: A - atacado, e B - varejo. 

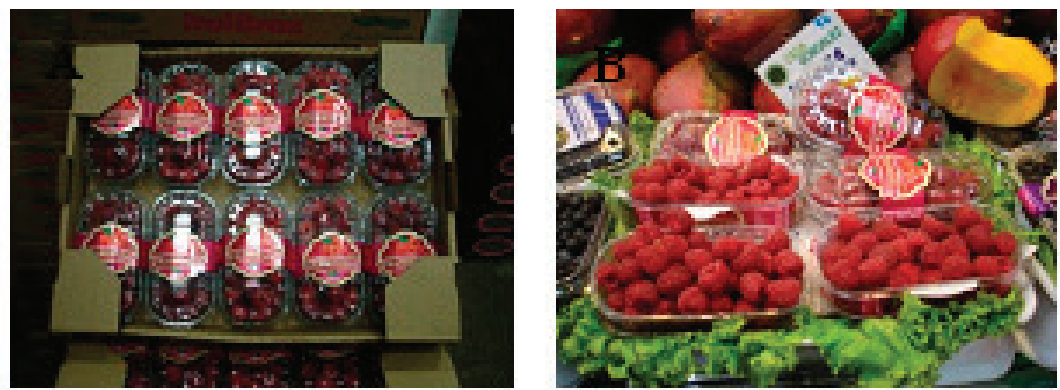

FIGURA 9- Venda de framboesa: A - atacado, e B - varejo.
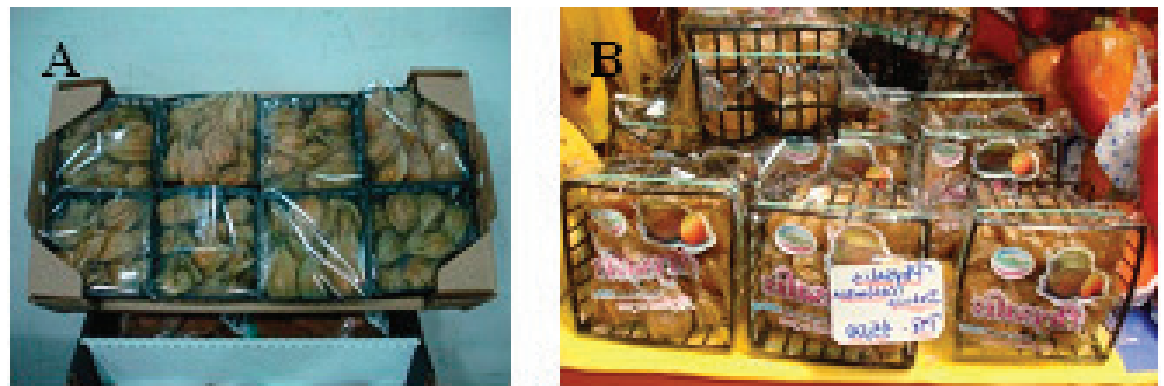

FIGURA 10- Venda de physalis: A - atacado, e B - varejo.

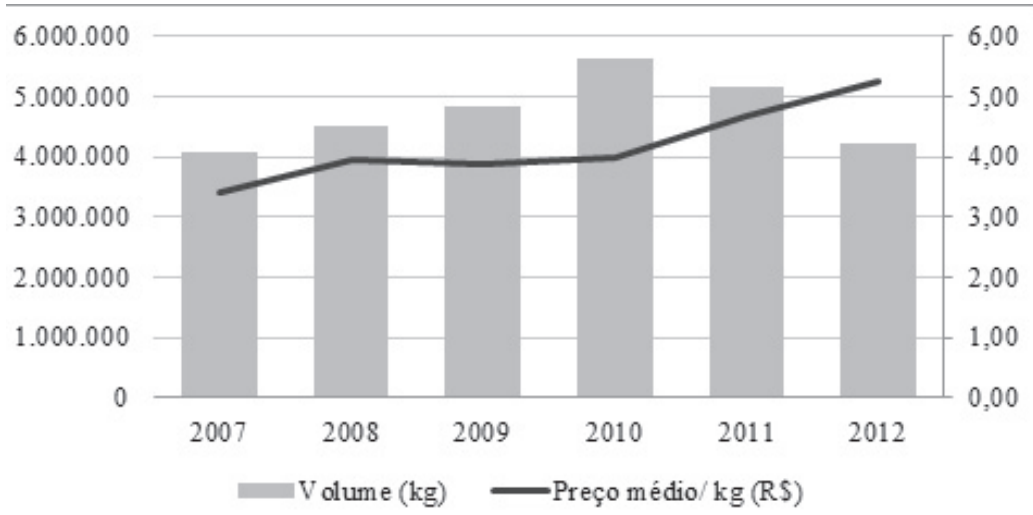

FIGURA 11- Evolução do volume e do preço médio da carambola comercializada na CEAGESP, de 2007 a 2012 .
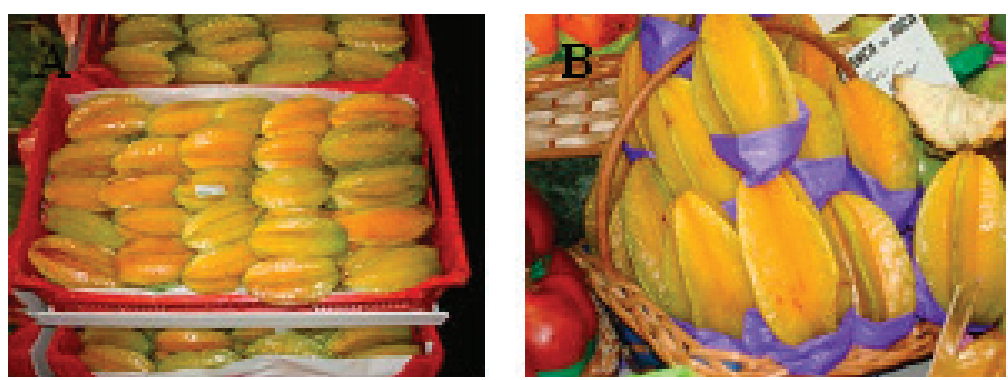

FIGURA 12- Venda de carambola: A - atacado, e B - varejo. 

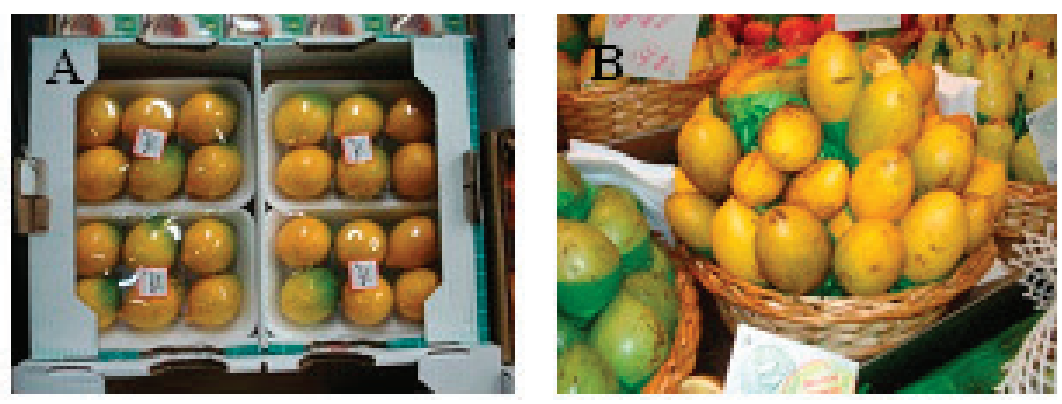

FIGURA 13 - Venda de abiu: A - atacado, e B - varejo.
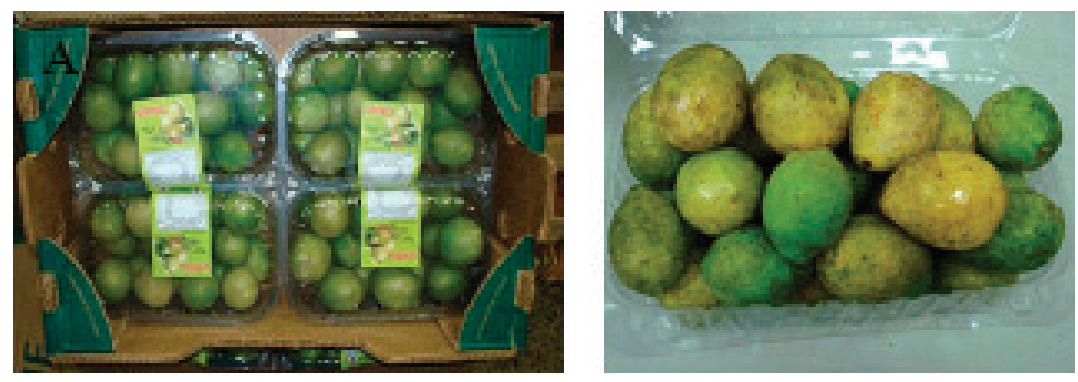

FIGURA 14 - Venda de umbu: A - atacado, e B - varejo. 
TABELA 1- Movimentação (kg) e valor (R\$) das frutas exóticas nas CEASAs do Sistema PROHORT 2011 e 2012 .

\begin{tabular}{|c|c|c|c|c|c|c|c|c|}
\hline \multirow[b]{2}{*}{ Produto } & \multicolumn{3}{|c|}{2011} & \multicolumn{3}{|c|}{2012} & \multicolumn{2}{|c|}{$\begin{array}{c}\text { Variação \% } \\
2011 / 2012\end{array}$} \\
\hline & $\begin{array}{c}\text { Volume } \\
\text { (kg) }\end{array}$ & $\begin{array}{c}\text { Valor } \\
\text { (RS) }\end{array}$ & $\begin{array}{c}\text { Preço/ } \\
\text { kg }\end{array}$ & $\begin{array}{c}\text { Volume } \\
(\mathrm{kg})\end{array}$ & $\begin{array}{c}\text { Valor } \\
\text { (RS) }\end{array}$ & $\begin{array}{c}\text { Preço/ } \\
\text { kg }\end{array}$ & $\begin{array}{c}\text { Volume } \\
(\mathrm{kg})\end{array}$ & Preço \\
\hline Abiu & 70.039 & 652.429 & 9,32 & 29.062 & 194.062 & 6,68 & $-58,51$ & $-28,32$ \\
\hline Açaí & 2.103 .937 & 4.422 .624 & 2,10 & 2.171 .463 & 14.595 .820 & 6,72 & 3,21 & 219,76 \\
\hline Acerola & 388.789 & 2.598 .090 & 6,68 & \begin{tabular}{|l|}
1.544 .599 \\
\end{tabular} & \begin{tabular}{|l|}
5.212 .171 \\
\end{tabular} & 3,37 & 297,28 & $-49,50$ \\
\hline Amora & 82.002 & 441.931 & 5,39 & 192.451 & 338.875 & 1,76 & 134,69 & $-67,33$ \\
\hline Araticum & 129.865 & 130.054 & 1,00 & 102.976 & 114.906 & 1,12 & $-20,71$ & 11,42 \\
\hline Biriba & 140 & 350 & 2,50 & 70 & 360 & 5,14 & $-50,00$ & 105,71 \\
\hline Cacau & 82.002 & 82.052 & 1,00 & 89.024 & 89.024 & 1,00 & 8,56 & $-0,06$ \\
\hline Cajá & 149.116 & 203.923 & 1,37 & 147.220 & 279.906 & 1,90 & $-1,27$ & 39,03 \\
\hline Cajamanga & 338.474 & 445.248 & 1,32 & 259.377 & 453.967 & 1,75 & $-23,37$ & 33,05 \\
\hline Cajarana & 70 & 143 & 2,04 & 4.504 & 9.049 & 2,01 & $6.334,29$ & $-1,65$ \\
\hline Carambola & 5.653 .528 & 24.931 .787 & 4,41 & 4.193 .211 & 19.575 .846 & 4,67 & $-25,83$ & 5,86 \\
\hline Cupuaçu & 20.172 & 127.307 & 6,31 & 7.217 & 47.169 & 6,54 & $-64,22$ & 3,56 \\
\hline Damasco & 842 & 842 & 1,00 & 260 & 260 & 1,00 & $-69,12$ & 0,00 \\
\hline Framboesa & 55.188 & 2.090 .879 & 37,89 & 45.058 & 935.663 & 20,77 & $-18,36$ & $-45,19$ \\
\hline Fruta-Pão & 12.540 & 9.954 & 0,79 & 10.200 & 8.640 & 0,85 & $-18,66$ & 6,72 \\
\hline Granadilla & 14.419 & 14.419 & 1,00 & 18.373 & 18.373 & 1,00 & 27,42 & 0,00 \\
\hline Groselha & 409 & 409 & 1,00 & 1.716 & 1.716 & 1,00 & 319,56 & 0,00 \\
\hline Ingá & 104 & 104 & 1,00 & 304 & 304 & 1,00 & 192,31 & 0,00 \\
\hline Jambo & 46.061 & 76.057 & 1,65 & 16.863 & 22.267 & 1,32 & $-63,39$ & $-20,03$ \\
\hline Jatobá & 2.778 & 2.778 & 1,00 & 831 & 831 & 1,00 & $-70,09$ & 0,00 \\
\hline Jenipap & 3.387 & 4.629 & 1,37 & 13.503 & 20.169 & 1,49 & 298,67 & 9,29 \\
\hline Kino & 9.012 & 9.012 & 1,00 & 17.116 & 17.116 & 1,00 & 89,92 & 0,00 \\
\hline Lichia & 2.816 .179 & 17.875 .118 & 6,35 & 877.858 & 5.687 .241 & 6,48 & $-68,83$ & 2,07 \\
\hline Mana & 507 & 507 & 1,00 & 1.156 & 1.156 & 1,00 & 128,01 & 0,00 \\
\hline Mangostin & 42.088 & 79.437 & 1,89 & 137.679 & 572.732 & 4,16 & 227,12 & 120,40 \\
\hline Mirtilo & 0 & 0 & 0,00 & 257 & 13.431 & 52,26 & 0,00 & 0,00 \\
\hline Murici & 0 & 0 & 0,00 & 1.760 & 8.113 & 4,61 & 0,00 & 0,00 \\
\hline Noni & 0 & 0 & 0,00 & 3.585 & 7.170 & 2,00 & 0,00 & 0,00 \\
\hline Pequi & \begin{tabular}{|l|}
3.472 .993 \\
\end{tabular} & 2.009 .927 & 0,58 & 1.218 .791 & 1.298 .601 & 1,07 & $-64,91$ & 84,11 \\
\hline Physalis & 381 & 13.416 & 35,21 & 380 & 11.835 & 31,14 & $-0,26$ & $-11,55$ \\
\hline Pitanga & 720 & 720 & 1,00 & 4.790 & 4.790 & 1,00 & 565,28 & 0,00 \\
\hline Pitaya & 237.579 & 248.669 & 1,05 & 279.281 & 297.909 & 1,07 & 17,55 & 1,91 \\
\hline Pitomba & 0 & 0 & 0,00 & 4.803 & 12.300 & 2,56 & 0,00 & 0,00 \\
\hline Pupunha & 4.561 & 5.371 & 1,18 & 8.437 & 54.574 & 6,47 & 84,98 & 449,34 \\
\hline Rambutã & 5.452 & 5.452 & 1,00 & 18.020 & 18.020 & 1,00 & 230,52 & 0,00 \\
\hline Romã & 412.850 & 4.319 .595 & 10,46 & 281.019 & 2.050 .118 & 7,30 & $-31,93$ & $-30,27$ \\
\hline Sapoti & 65.932 & 291.598 & 4,42 & 34.834 & 90.147 & 2,59 & $-47,17$ & $-41,49$ \\
\hline Seriguela & 172.298 & 224.960 & 1,31 & 298.761 & 493.897 & 1,65 & 73,40 & 26,62 \\
\hline Tamarillo & 3.206 & 3.206 & 1,00 & 2.739 & 2.739 & 1,00 & $-14,57$ & 0,00 \\
\hline Tamarindo & 110.353 & 218.636 & 1,98 & 86.061 & 131.027 & 1,52 & $-22,01$ & $-23,16$ \\
\hline Umbu & 10.634 & 10.634 & 1,00 & 0 & 0 & 0,00 & $-100,00$ & $-100,00$ \\
\hline Zabão & 10.634 & 10.634 & 1,00 & 11.752 & 11.752 & 1,00 & 0,00 & 0,00 \\
\hline
\end{tabular}

Fonte: PROGRAMA BRASILEIRO DE MODERNIZAÇÃO DO MERCADO HORTIGRANJEIRO, 2013. 
Tabela 2: Classificação em relação a todas as frutas e o volume comercializado em toneladas das frutas exóticas na CEAGESP, em 2012

\begin{tabular}{ccc|ccc}
\hline Classificação & Produto & Volume (t) & Classificação & Produto & Volume (t) \\
\hline $25^{\circ}$ & Carambola & 4.224 & $55^{\circ}$ & Umbu & 36 \\
$27^{\circ}$ & Jabuticaba & 2.231 & $57^{\circ}$ & Physalis & 32 \\
$29^{\circ}$ & Lichia & 1.838 & $58^{\circ}$ & Sapoti & 27 \\
$36^{\circ}$ & Romã & 561 & $60^{\circ}$ & Granadilla & 21 \\
$37^{\circ}$ & Acerola & 436 & $61^{\circ}$ & Kino & 19 \\
$39^{\circ}$ & Graviola & 346 & $62^{\circ}$ & Rambutã & 18 \\
$40^{\circ}$ & Pitaya & 299 & $63^{\circ}$ & Abiu & 14 \\
$41^{\circ}$ & Mangostão & 288 & $64^{\circ}$ & Jambo & 10 \\
$42^{\circ}$ & Amora & 259 & $65^{\circ}$ & Pitanga & 6 \\
$43^{\circ}$ & Grape Fruit & 258 & $66^{\circ}$ & Tamarillo & 4 \\
$44^{\circ}$ & Kinkan & 197 & $67^{\circ}$ & Jenipapo & 4 \\
$47^{\circ}$ & Seriguela & 174 & $68^{\circ}$ & Feijoa & 2 \\
$49^{\circ}$ & Tâmara & 111 & $69^{\circ}$ & Jatobá & 2 \\
$50^{\circ}$ & Cupuaçu & 106 & $71^{\circ}$ & Mana & 1,4 \\
$51^{\circ}$ & Tamarindo & 96 & $72^{\circ}$ & Cherimólia & 1,3 \\
$53^{\circ}$ & Mirtilo & 52 & $73^{\circ}$ & Ingá & 0,3 \\
$54^{\circ}$ & Framboesa & 48 & & & \\
\hline Total (t) & 11.524 & \multicolumn{5}{c}{} \\
\hline Total (t) 1+2 & \multicolumn{5}{c}{}
\end{tabular}

Fonte: SISTEMA DE INFORMAÇÃO E ESTATÍSTICA DE MERCADO, 2013.

TABELA 3- Classificação em relação a todas as frutas e volume financeiro (R\$) das frutas exóticas na CEAGESP, em 2012.

\begin{tabular}{|c|c|c|c|c|c|}
\hline Classificação & Produto & Valor (R\$) & Classificação & Produto & Valor (R\$) \\
\hline $24^{\circ}$ & Jabuticaba & 19.516 .565 & $57^{\circ}$ & Physalis & 117.812 \\
\hline $26^{\circ}$ & Carambola & 15.119 .276 & $58^{\circ}$ & Abiu & 98.571 \\
\hline $29^{\circ}$ & Lichia & 10.329 .495 & $59^{\circ}$ & Kino & 93.666 \\
\hline $35^{\circ}$ & Romã & 3.651 .916 & $60^{\circ}$ & Sapoti & 83.133 \\
\hline $36^{\circ}$ & Amora & 3.117 .840 & $61^{\circ}$ & Umbu & 80.680 \\
\hline $38^{\circ}$ & Acerola & 2.056 .463 & $62^{\circ}$ & Jambo & 59.110 \\
\hline $40^{\circ}$ & Pitaya & 1.295 .457 & $63^{\circ}$ & Rambutã & 54.817 \\
\hline $41^{\circ}$ & Framboesa & 1.284 .346 & $64^{\circ}$ & Granadilla & 53.552 \\
\hline $43^{\circ}$ & Mangostão & 1.086 .506 & $65^{\circ}$ & Pitanga & 23.741 \\
\hline $44^{\circ}$ & Kinkan & 1.080 .629 & $66^{\circ}$ & Jenipapo & 20.999 \\
\hline $45^{\circ}$ & Graviola & 1.071 .610 & $67^{\circ}$ & Tamarillo & 14.016 \\
\hline $46^{\circ}$ & Grape-Fruit & 779.130 & $68^{\circ}$ & Jatoba & 11.562 \\
\hline $47^{\circ}$ & Tâmara & 627.829 & $69^{\circ}$ & Mana & 5.352 \\
\hline $48^{\circ}$ & Seriguela & 527.623 & $71^{\circ}$ & Feijoa & 4.473 \\
\hline $50^{\circ}$ & Cupuaçu & 397.560 & $72^{\circ}$ & Cherimólia & 4.455 \\
\hline $51^{\circ}$ & Tamarindo & 361.140 & $73^{\circ}$ & Ingá & 834 \\
\hline $52^{\circ}$ & Mirtilo & 298.003 & \multicolumn{3}{|l}{} \\
\hline Total & & 62.601 .388 & & & 726.773 \\
\hline Total & \multicolumn{5}{|l|l|}{} \\
\cline { 2 - 6 } & & 63.328 .161 & & \\
\hline
\end{tabular}

Fonte: SISTEMA DE INFORMAÇÃO E ESTATÍSTICA DE MERCADO, 2013. 
TABELA 4- Sazonalidade do volume da lichia comercializada na CEAGESP, de 2007 a 2012.

\begin{tabular}{|l|c|c|c|c|c|c|c|c|c|c|c|c|}
\hline Ano & Jan. & Fev. & Mar. & Abr. & Maio & Jun. & Jul. & Ago. & Set. & Out. & Nov. & Dez. \\
\hline 2007 & 232 & -86 & -94 & -100 & -100 & -100 & -100 & -100 & -100 & -100 & -52 & 699 \\
\hline 2008 & 189 & -50 & -99 & -100 & -100 & -100 & -100 & -100 & -100 & -96 & 47 & 610 \\
\hline 2009 & 110 & -86 & -92 & -100 & -100 & -100 & -100 & -100 & -100 & -100 & 52 & 715 \\
\hline 2010 & 292 & -61 & -98 & -100 & -100 & -100 & -100 & -100 & -100 & -99 & -14 & 579 \\
\hline 2011 & 282 & -61 & -94 & -100 & -100 & -100 & -100 & -100 & -100 & -97 & 47 & 524 \\
\hline 2012 & 260 & -54 & -99 & -99 & -100 & -100 & -100 & -100 & -100 & -95 & 51 & 536 \\
\hline
\end{tabular}

Fonte: SISTEMA DE INFORMAÇÃO E ESTATÍSTICA DE MERCADO, 2013.

TABELA 5- Sazonalidade de valor da lichia comercializada na CEAGESP, de 2007 a 2012

\begin{tabular}{|c|c|c|c|c|c|c|c|c|c|c|c|c|}
\hline Ano & Jan. & Fev. & Mar. & Abr. & Maio & Jun. & Jul. & Ago. & Set. & Out. & Nov. & Dez. \\
\hline 2007 & -31 & -100 & -100 & -100 & -100 & -100 & -100 & -100 & -100 & -100 & 47 & -17 \\
\hline 2008 & -32 & -100 & -100 & -100 & -100 & -100 & -100 & -100 & -100 & -100 & 49 & -17 \\
\hline 2009 & -50 & 10 & 40 & -100 & -100 & -100 & -100 & -100 & -100 & -100 & -100 & -100 \\
\hline 2010 & -63 & -44 & -100 & -100 & -100 & -100 & -100 & -100 & -100 & 148 & 2 & -43 \\
\hline 2011 & -62 & -20 & -100 & -100 & -100 & -100 & -100 & -100 & -100 & 141 & -9 & -50 \\
\hline 2012 & -29 & 8 & -100 & -100 & -100 & -100 & -100 & -100 & -100 & -100 & 45 & -24 \\
\hline
\end{tabular}

Fonte: SISTEMA DE INFORMAÇÃO E ESTATÍSTICA DE MERCADO, 2013.

TABELA 6- Sazonalidade do volume (\%) da romã em relação ao volume médio comercializado na CEAGESP, de 2008 a 2012.

\begin{tabular}{|c|c|c|c|c|c|c|c|c|c|c|c|c|}
\hline Ano & Jan. & Fev. & Mar. & Abr. & Maio & Jun. & Jul. & Ago. & Set. & Out. & Nov. & Dez. \\
\hline 2.008 & 10 & -16 & -7 & -43 & -12 & -38 & -65 & -66 & -14 & -57 & -2 & 311 \\
\hline 2.009 & 126 & 43 & -18 & -26 & -19 & -51 & -55 & -56 & -68 & -76 & -39 & 294 \\
\hline 2.010 & -7 & -33 & -49 & -58 & -27 & -36 & -63 & -16 & 26 & -41 & 22 & 823 \\
\hline 2.011 & -20 & 50 & 36 & -68 & -83 & -84 & -83 & -25 & -23 & -25 & 148 & 459 \\
\hline 2.012 & 3 & -9 & 11 & 24 & -21 & -28 & -57 & -29 & -51 & -36 & 176 & 473 \\
\hline
\end{tabular}

Fonte: SISTEMA DE INFORMAÇÃO E ESTATÍSTICA DE MERCADO, 2013.

TABELA 7- Sazonalidade do valor da romã comercializada na CEAGESP de 2008 a 2012.

\begin{tabular}{|c|c|c|c|c|c|c|c|c|c|c|c|c|}
\hline Ano & Jan. & Fev. & Mar. & Abr. & Maio & Jun. & Jul. & Ago. & Set. & Out. & Nov. & Dez. \\
\hline 2008 & -25 & -54 & -14 & 17 & -2 & -4 & -7 & -2 & 29 & 35 & 11 & 15 \\
\hline 2009 & 6 & -44 & -35 & -22 & -21 & -27 & 7 & 33 & 40 & 30 & 26 & 8 \\
\hline 2010 & 29 & -18 & -10 & 5 & 42 & -8 & -13 & -8 & -25 & -12 & 6 & 14 \\
\hline 2011 & 28 & -21 & -51 & -55 & 8 & 60 & 31 & 40 & 16 & -31 & -18 & -7 \\
\hline 2012 & 8 & -37 & -22 & -13 & -16 & -6 & -11 & 22 & 39 & 4 & 2 & 29 \\
\hline
\end{tabular}

Fonte: SISTEMA DE INFORMAÇÃO E ESTATÍSTICA DE MERCADO, 2013. 
TABELA 8-Evolução do volume em quilos de rambutã comercializada na CEAGESP, de 2007 a 2012.

\begin{tabular}{|c|c|c|c|c|c|c|}
\hline & 2007 & 2008 & 2009 & 2010 & 2011 & 2012 \\
\hline Mês & $\begin{array}{c}\text { Volume } \\
\text { kg }\end{array}$ & $\begin{array}{l}\text { Volu- } \\
\text { me kg }\end{array}$ & $\begin{array}{c}\text { Volume } \\
\text { kg }\end{array}$ & $\begin{array}{c}\text { Volume } \\
\text { kg }\end{array}$ & $\begin{array}{c}\text { Volume } \\
\text { kg }\end{array}$ & Volume kg \\
\hline Janeiro & 2.320 & 432 & 376 & 1.193 & 83 & 248 \\
\hline Fevereiro & 92 & 329 & 169 & 150 & 347 & 166 \\
\hline Março & 336 & 34 & 528 & 277 & 438 & 1.055 \\
\hline Abril & 965 & 305 & 3.271 & 660 & 1.542 & 2.466 \\
\hline Maio & 780 & 1.084 & 3.948 & 5.537 & 704 & 829 \\
\hline Junho & 3.799 & 120 & 2.032 & 11.045 & 470 & 4.700 \\
\hline Julho & 3.278 & 1.207 & 600 & 2.238 & 0 & 4.385 \\
\hline Agosto & 5.152 & 3.481 & 0 & 316 & 100 & 3.635 \\
\hline Setembro & 893 & 120 & 0 & 5 & 1.206 & 475 \\
\hline Outubro & 0 & 0 & 0 & 0 & 216 & 61 \\
\hline Novembro & 0 & 0 & 0 & 55 & 60 & 25 \\
\hline Dezembro & 86 & 130 & 448 & 190 & 286 & 1 \\
\hline Total & 17.701 & 7.242 & 11.372 & 21.666 & 5.452 & 18.046 \\
\hline
\end{tabular}

Fonte: SISTEMA DE INFORMAÇÃO E ESTATÍSTICA DE MERCADO, 2013.

TABELA 9- Sazonalidade do volume (\%) da rambuã comercializada na CEAGESP, de 2007 a 2012.

\begin{tabular}{|c|c|c|c|c|c|c|c|c|c|c|c|c|}
\hline Ano & Jan. & Fev. & Mar. & Abr. & Maio & Jun. & Jul. & Ago. & Set. & Out. & Nov. & Dez. \\
\hline 2007 & 57 & -94 & -77 & -35 & -47 & 158 & 122 & 249 & -39 & -100 & -100 & -94 \\
\hline 2008 & -28 & -45 & -94 & -49 & 80 & -80 & 100 & 477 & -80 & -100 & -100 & -78 \\
\hline 2009 & -60 & -82 & -44 & 245 & 317 & 114 & -37 & -100 & -100 & -100 & -100 & -53 \\
\hline 2010 & -34 & -92 & -85 & -63 & 207 & 512 & 24 & -82 & -100 & -100 & -97 & -89 \\
\hline 2011 & 83 & 347 & 438 & 1.542 & 704 & 470 & 0 & 100 & 1.206 & 216 & 60 & 286 \\
\hline 2012 & 248 & 166 & 1.055 & 2.466 & 829 & 4.700 & 4.385 & 3.635 & 475 & 61 & 25 & 1 \\
\hline
\end{tabular}

Fonte: SISTEMA DE INFORMAÇÃO E ESTATÍSTICA DE MERCADO, 2013.

TABELA 10- Evolução do volume da mangostão comercializado na CEAGESP, de 2007 a 2012

\begin{tabular}{|l|c|c|c|c|c|c|}
\hline Mês & $\begin{array}{c}\mathbf{2 0 0 7} \\
\text { Volume kg }\end{array}$ & $\begin{array}{c}\mathbf{2 0 0 8} \\
\text { Volume kg }\end{array}$ & $\begin{array}{c}\mathbf{2 0 0 9} \\
\text { Volume kg }\end{array}$ & $\begin{array}{c}\mathbf{2 0 1 0} \\
\text { Volume kg }\end{array}$ & $\begin{array}{c}\mathbf{2 0 1 1} \\
\text { Volume kg }\end{array}$ & $\begin{array}{c}\mathbf{2 0 1 2} \\
\text { Volume kg }\end{array}$ \\
\hline Janeiro & 641 & 8.921 & 36.600 & 2.999 & 191 & 17.441 \\
\hline Fevereiro & 516 & 3.292 & 530 & 4.810 & 1.073 & 9.390 \\
\hline Março & 6.657 & 15.918 & 5.995 & 3.234 & 28.072 & 51.316 \\
\hline Abril & 12.733 & 32.270 & 35.347 & 3.409 & 2.626 & 7.166 \\
\hline Maio & 3.688 & 34.229 & 16.751 & 60.299 & 0 & 8 \\
\hline Junho & 3.952 & 0 & 685 & 101.696 & 0 & 55 \\
\hline Julho & 2.478 & 1.855 & 172 & 40.783 & 0 & 4.366 \\
\hline Agosto & 24.305 & 7.692 & 12 & 14.666 & 10 & 20.431 \\
\hline Setembro & 3.016 & 9.636 & 0 & 344 & 1.604 & 5.524 \\
\hline Outubro & 485 & 186 & 0 & 23 & 715 & 4.877 \\
\hline Novembro & 92 & 7.433 & 1.562 & 869 & 2.698 & 81.802 \\
\hline Dezembro & 4.481 & 79.717 & 7.234 & 265 & 3.197 & 86.384 \\
\hline Total & 63.044 & 201.149 & 104.888 & 233.397 & 40.186 & 288.760 \\
\hline
\end{tabular}

Fonte: SISTEMA DE INFORMAÇÃO E ESTATÍSTICA DE MERCADO, 2013. 
TABELA 11- Sazonalidade do volume (\%) do mangostão em relação ao volume médio comercializado na CEAGESP, de 2007 a 2012.

\begin{tabular}{|c|c|c|c|c|c|c|c|c|c|c|c|c|}
\hline Ano & Jan. & Fev. & Mar. & Abr. & Maio & Jun. & Jul. & Ago. & Set. & Out. & Nov. & Dez. \\
\hline 2007 & -88 & -90 & 27 & 142 & -30 & -25 & -53 & 363 & -43 & -91 & -98 & -15 \\
\hline 2008 & -47 & -80 & -5 & 93 & 104 & -100 & -89 & -54 & -43 & -99 & -56 & 376 \\
\hline 2009 & 319 & -94 & -31 & 304 & 92 & -92 & -98 & -100 & -100 & -100 & -82 & -17 \\
\hline 2010 & -85 & -75 & -83 & -82 & 210 & 423 & 110 & -25 & -98 & -100 & -96 & -99 \\
\hline 2011 & -94 & -68 & 738 & -22 & -100 & -100 & -100 & -100 & -52 & -79 & -19 & -5 \\
\hline 2012 & -28 & -61 & 113 & -70 & -100 & -100 & -82 & -15 & -77 & -80 & 240 & 259 \\
\hline
\end{tabular}

Fonte: SISTEMA DE INFORMAÇÃO E ESTATÍSTICA DE MERCADO, 2013.

TABELA 12- Evolução do volume e preço médio da pitaya comercializada na CEAGESP, de 2007 a 2012

\begin{tabular}{|l|c|c|c|c|c|c|}
\hline Mês & $\mathbf{2 0 0 7}$ & $\mathbf{2 0 0 8}$ & $\mathbf{2 0 0 9}$ & $\mathbf{2 0 1 0}$ & $\mathbf{2 0 1 1}$ & $\mathbf{2 0 1 2}$ \\
\hline Janeiro & Volume kg & Volume kg & Volume kg & Volume kg & Volume kg & Volume kg \\
\hline Fevereiro & 15.138 & 5.037 & 24.444 & 42.531 & 49.647 & 48.411 \\
\hline Março & 34.104 & 22.458 & 32.067 & 19.239 & 66.381 & 56.301 \\
\hline Abril & 8.988 & 5.511 & 11.946 & 33.240 & 55.017 & 59.553 \\
\hline Maio & 1.485 & 4.560 & 11.130 & 8.289 & 8.973 & 26.247 \\
\hline Junho & 156 & 2.319 & 8.295 & 4.488 & 1.626 & 3.687 \\
\hline Julho & 228 & 405 & 1.989 & 1.335 & 1.221 & 9.867 \\
\hline Agosto & 0 & 903 & 714 & 648 & 924 & 1.965 \\
\hline Setembro & 72 & 330 & 729 & 1.722 & 2.850 & 6.720 \\
\hline Outubro & 1.140 & 987 & 2.787 & 1.440 & 2.031 & 4.599 \\
\hline Novembro & 1.031 & 753 & 2.478 & 2.043 & 2.151 & 2.442 \\
\hline Dezembro & 9.612 & 13.299 & 9.519 & 14.214 & 27.462 & 20.274 \\
\hline Total & 81.582 & 75.768 & 115.488 & 152.568 & 235.884 & 299.100 \\
\hline
\end{tabular}

Fonte: SISTEMA DE INFORMAÇÃO E ESTATÍSTICA DE MERCADO, 2013.

TABELA 13- Sazonalidade do volume (\%) da pitaya em relação ao volume médio comercializado na CEAGESP, de 2007 a 2012.

\begin{tabular}{|c|c|c|c|c|c|c|c|c|c|c|c|c|}
\hline Ano & Jan. & Fev. & Mar. & Abr. & Maio & Jun. & Jul. & Ago. & Set. & Out. & Nov. & Dez. \\
\hline 2007 & 34 & 130 & 402 & 32 & -78 & -98 & -97 & -100 & -99 & -83 & -85 & 41 \\
\hline 2008 & -20 & 256 & 204 & -13 & -28 & -63 & -94 & -86 & -95 & -84 & -88 & 111 \\
\hline 2009 & 154 & 233 & -2 & 24 & 16 & -14 & -79 & -93 & -92 & -71 & -74 & -1 \\
\hline 2010 & 235 & 51 & 84 & 161 & -35 & -65 & -89 & -95 & -86 & -89 & -84 & 12 \\
\hline 2011 & 153 & 238 & -10 & 180 & -54 & -92 & -94 & -95 & -86 & -90 & -89 & 40 \\
\hline 2012 & 94 & 126 & 137 & 139 & 5 & -85 & -60 & -92 & -73 & -82 & -90 & -19 \\
\hline
\end{tabular}

Fonte: SISTEMA DE INFORMAÇÃO E ESTATÍSTICA DE MERCADO, 2013. 
TABELA 14- Evolução do volume da amora comercializada na CEAGESP, de 2007 a 2012.

\begin{tabular}{|l|c|c|c|c|c|c|}
\hline & $\mathbf{2 0 0 7}$ & $\mathbf{2 0 0 8}$ & $\mathbf{2 0 0 9}$ & $\mathbf{2 0 1 0}$ & $\mathbf{2 0 1 1}$ & $\mathbf{2 0 1 2}$ \\
\hline \multicolumn{1}{|c|}{ Mês } & Volume kg & Volume kg & Volume kg & Volume kg & Volume kg & Volume kg \\
\hline Janeiro & 6.035 & 14.040 & 20.584 & 19.980 & 25.132 & 18.204 \\
\hline Fevereiro & 2.058 & 3.920 & 7.064 & 12.468 & 6.872 & 13.100 \\
\hline Março & 898 & 2.056 & 5.732 & 9.656 & 11.236 & 14.524 \\
\hline Abril & 1.564 & 1.116 & 4.544 & 720 & 5.240 & 7.336 \\
\hline Maio & 424 & 20 & 372 & 1.684 & 2.892 & 8.592 \\
\hline Junho & 1.372 & 56 & 1.304 & 3.464 & 7.644 & 8.724 \\
\hline Julho & 1.348 & 365 & 1.996 & 2.368 & 8.988 & 7.456 \\
\hline Agosto & 32 & 312 & 2.156 & 6.996 & 8.408 & 14.616 \\
\hline Setembro & 2.896 & 10.460 & 7.792 & 12.720 & 18.172 & 23.628 \\
\hline Outubro & 8.084 & 15.372 & 33.508 & 27.552 & 34.360 & 60.004 \\
\hline Novembro & 34.268 & 46.440 & 92.952 & 53.172 & 40.716 & 57.944 \\
\hline Dezembro & 64.124 & 53.028 & 71.640 & 63.652 & 43.008 & 25.692 \\
\hline Total & 123.103 & 147.185 & 249.644 & 214.432 & 212.668 & 259.820 \\
\hline
\end{tabular}

Fonte: SISTEMA DE INFORMAÇÃO E ESTATÍSTICA DE MERCADO, 2013.

TABELA 15- Sazonalidade do volume (\%) da amora comercializada na CEAGESP, de 2007 a 2012

\begin{tabular}{|c|c|c|c|c|c|c|c|c|c|c|c|c|}
\hline Mês & Jan. & Fev. & Mar. & Abr. & Maio & Jun. & Jul. & Ago. & Set. & Out. & Nov. & Dez. \\
\hline 2007 & -41 & -80 & -91 & -85 & -96 & -87 & -87 & -100 & -72 & -21 & 234 & -41 \\
\hline 2008 & 14 & -68 & -83 & -91 & -100 & -100 & -97 & -97 & -15 & 25 & 279 & 14 \\
\hline 2009 & -1 & -66 & -72 & -78 & -98 & -94 & -90 & -90 & -63 & 61 & 347 & -1 \\
\hline 2010 & 12 & -40 & -54 & -97 & -92 & -83 & -89 & -66 & -39 & 32 & 156 & 12 \\
\hline 2011 & 42 & -61 & -37 & -70 & -84 & -57 & -49 & -53 & 3 & 94 & 130 & 42 \\
\hline 2012 & -16 & -39 & -33 & -66 & -60 & -60 & -66 & -32 & 9 & 177 & 168 & -16 \\
\hline
\end{tabular}

Fonte: SISTEMA DE INFORMAÇÃO E ESTATÍSTICA DE MERCADO, 2013.

TABELA 16- Evolução do preço médio e do volume em quilos da framboesa comercializada na CEAGESP, entre 2007 e 2012.

\begin{tabular}{|c|c|c|c|c|c|c|c|c|c|c|c|c|}
\hline & \multicolumn{2}{|c|}{2007} & \multicolumn{2}{|c|}{2008} & \multicolumn{2}{|c|}{2009} & \multicolumn{2}{|c|}{2010} & \multicolumn{2}{|c|}{2011} & \multicolumn{2}{|c|}{2012} \\
\hline Mês & $\mathrm{R} \$ / \mathrm{kg}$ & $\begin{array}{c}\text { Volume } \\
\mathrm{kg}\end{array}$ & $\mathrm{R} \$ \mathbf{k g}$ & $\begin{array}{c}\text { Volume } \\
\mathrm{kg}\end{array}$ & R\$/kg & $\begin{array}{c}\text { Volume } \\
\text { kg }\end{array}$ & R\$/kg & $\begin{array}{c}\text { Volume } \\
\text { kg }\end{array}$ & $\mathrm{R} \$ / \mathbf{k g}$ & $\underset{\mathrm{kg}}{\text { Volume }}$ & $\mathrm{R} \$ / \mathrm{kg}$ & $\begin{array}{c}\text { Volume } \\
\text { kg }\end{array}$ \\
\hline Janeiro & - & 3.961 & - & 3.330 & - & 2.742 & - & 7.077 & - & 2.523 & 56,57 & 5.976 \\
\hline Fevereiro & - & 2.681 & - & 3.051 & - & 5.850 & - & 2.106 & 40,55 & 3.555 & 49,29 & 4.026 \\
\hline Março & - & 14.016 & - & 1.758 & - & 4.935 & - & 1.323 & 38,04 & 3.162 & 50,36 & 3.165 \\
\hline Abril & - & 1.437 & - & 375 & - & 1.833 & - & 1.566 & 37,09 & 3.552 & 64,12 & 3.192 \\
\hline Maio & - & 495 & - & 33 & - & 54 & - & 2.691 & - & 4.812 & - & 3.975 \\
\hline Junho & - & 744 & & 480 & - & 1.368 & - & 1.539 & - & 4.377 & - & 4.860 \\
\hline Julho & - & 1.044 & & 270 & - & 1.551 & - & 918 & 56,38 & 5.853 & - & 6.309 \\
\hline Agosto & - & - & - & - & - & 2.016 & - & 1.086 & 59,01 & 6.069 & - & 5.247 \\
\hline Setembro & - & 216 & - & 333 & - & 954 & - & 1.071 & 57,00 & 3.441 & - & 4.026 \\
\hline Outubro & - & 1.752 & - & 6.237 & - & 1.440 & - & 183 & & 2.487 & - & 2.682 \\
\hline Novembro & - & 4.782 & - & 4.170 & - & 5.532 & - & 1.446 & 46,25 & 5.349 & 47,06 & 2.592 \\
\hline Dezembro & - & 6.168 & - & 9.147 & - & 8.760 & 43,62 & 4.626 & 40,31 & 6.408 & 40,00 & 2.379 \\
\hline Total & 0,00 & 37.296 & 0,00 & 29.184 & 0,00 & 37.035 & 43,62 & 25.632 & 374,63 & 51.588 & 307,40 & 48.429 \\
\hline $\begin{array}{l}\text { Média } \\
\text { Mensal }\end{array}$ & 0,00 & 3.391 & 0,00 & 2.653 & 0,00 & 3.086 & 43,62 & 2.136 & 46,83 & 4.299 & 51,23 & 4.036 \\
\hline
\end{tabular}

Fonte: SISTEMA DE INFORMAÇÃO E ESTATÍSTICA DE MERCADO, 2013. 
TABELA 17- Sazonalidade do volume (\%) da framboesa comercializada na CEAGESP, de 2007 a 2012.

\begin{tabular}{|c|c|c|c|c|c|c|c|c|c|c|c|c|}
\hline Ano & Jan. & Fev. & Mar. & Abr. & Maio & Jun. & Jul. & Ago. & Set. & Out. & Nov. & Dez. \\
\hline 2007 & 27 & -14 & 351 & -54 & -84 & -76 & -66 & -100 & -93 & -44 & 54 & 98 \\
\hline 2008 & 37 & 25 & -28 & -85 & -99 & -80 & -89 & -100 & -86 & 156 & 71 & 276 \\
\hline 2009 & -11 & 90 & 60 & -41 & -98 & -56 & -50 & -35 & -69 & -53 & 79 & 184 \\
\hline 2010 & 231 & -1 & -38 & -27 & 26 & -28 & -57 & -49 & -50 & -91 & -32 & 117 \\
\hline 2011 & -41 & -17 & -26 & -17 & 12 & 2 & 36 & 41 & -20 & -42 & 24 & 49 \\
\hline 2012 & 48 & -0 & -22 & -21 & -2 & 20 & 56 & 30 & -0 & -34 & -36 & -41 \\
\hline
\end{tabular}

Fonte: SISTEMA DE INFORMAÇÃO E ESTATÍSTICA DE MERCADO, 2013.

TABELA 18- Sazonalidade de valor da framboesa comercializada na CEAGESP, de 2007 a 2012.

\begin{tabular}{|l|c|c|c|c|c|c|c|c|c|c|c|c|}
\hline Ano & Jan. & Fev. & Mar. & Abr. & Maio & Jun. & Jul. & Ago. & Set. & Out. & Nov. & Dez. \\
\hline 2007 & 0 & 0 & 0 & 0 & 0 & 0 & 0 & 0 & 0 & 0 & 0 & 0 \\
\hline 2008 & 0 & 0 & 0 & 0 & 0 & 0 & 0 & 0 & 0 & 0 & 0 & 0 \\
\hline 2009 & 0 & 0 & 0 & 0 & 0 & 0 & 0 & 0 & 0 & 0 & 0 & 0 \\
\hline 2010 & 0 & 0 & 0 & 0 & 0 & 0 & 0 & 0 & 0 & 0 & 0 & 0 \\
\hline 2011 & 0 & 48 & 45 & 43 & 0 & 0 & 65 & 67 & 63 & 0 & 51 & 44 \\
\hline 2012 & 61 & 52 & 53 & 67 & 0 & 0 & 0 & 0 & 0 & 0 & 47 & 40 \\
\hline
\end{tabular}

Fonte: SISTEMA DE INFORMAÇÃO E ESTATÍSTICA DE MERCADO, 2013.

TABELA 19- Evolução do volume da physalis comercializada na CEAGESP, de 2007 a 2012.

\begin{tabular}{|l|c|c|c|c|c|c|}
\hline & $\mathbf{2 0 0 7}$ & $\mathbf{2 0 0 8}$ & $\mathbf{2 0 0 9}$ & $\mathbf{2 0 1 0}$ & $\mathbf{2 0 1 1}$ & $\mathbf{2 0 1 2}$ \\
\hline Mês & Volume kg & Volume kg & Volume kg & Volume kg & Volume kg & Volume kg \\
\hline Janeiro & 78 & 14 & 126 & 1.840 & 2.386 & 2.846 \\
\hline Fevereiro & 68 & 346 & 507 & 714 & 549 & 2.535 \\
\hline Março & 91 & 181 & 1.225 & 664 & 1.797 & 2.238 \\
\hline Abril & 50 & 480 & 1.400 & 1.531 & 986 & 2.166 \\
\hline Maio & 27 & 51 & 1.035 & 1.121 & 926 & 2.240 \\
\hline Junho & 605 & 868 & 286 & 893 & 1.410 & 1.605 \\
\hline Julho & 102 & 730 & 1.368 & 1.247 & 1.331 & 1.326 \\
\hline Agosto & 24 & 722 & 894 & 980 & 1.167 & 1.783 \\
\hline Setembro & 420 & 520 & 1.618 & 1.594 & 1.971 & 2.597 \\
\hline Outubro & 760 & 960 & 1.418 & 3.112 & 2.534 & 2.726 \\
\hline Novembro & 308 & 1 & 478 & 1.465 & 2.784 & 3.368 \\
\hline Dezembro & 0 & 2.818 & 880 & 2.134 & 4.593 & 5.923 \\
\hline Total & 2.533 & 7.691 & 11.235 & 17.295 & 22.434 & 31.353 \\
\hline
\end{tabular}

Fonte: SISTEMA DE INFORMAÇÃO E ESTATÍSTICA DE MERCADO, 2013. 
TABELA 20- Sazonalidade do volume (\%) da physalis comercializada na CEAGESP, de 2007 a 2012

\begin{tabular}{|c|c|c|c|c|c|c|c|c|c|c|c|c|}
\hline Ano & Jan. & Fev. & Mar. & Abr. & Maio & Jun. & Jul. & Ago. & Set. & Out. & Nov. & Dez. \\
\hline 2007 & -63 & -68 & -57 & -76 & -87 & 187 & -52 & -89 & 99 & 260 & 46 & -100 \\
\hline 2008 & -98 & -46 & -72 & -25 & -92 & 35 & 14 & 13 & -19 & 50 & -100 & 340 \\
\hline 2009 & -87 & -46 & 31 & 50 & 11 & -69 & 46 & -5 & 73 & 51 & -49 & -6 \\
\hline 2010 & 28 & -50 & -54 & 6 & -22 & -38 & -13 & -32 & 11 & 116 & 2 & 48 \\
\hline 2011 & 28 & -71 & -4 & -47 & -50 & -25 & -29 & -38 & 5 & 36 & 49 & 146 \\
\hline 2012 & 9 & -3 & -14 & -17 & -14 & -39 & -49 & -32 & -1 & 4 & 29 & 127 \\
\hline
\end{tabular}

Fonte: SISTEMA DE INFORMAÇÃO E ESTATÍSTICA DE MERCADO, 2013.

TABELA 21- Sazonalidade do volume da carambola comercializada na CEAGESP, de 2007 a 2012.

\begin{tabular}{|l|c|c|c|c|c|c|c|c|c|c|c|c|}
\hline Ano & Jan. & Fev. & Mar. & Abr. & Maio & Jun. & Jul. & Ago. & Set. & Out. & Nov. & Dez. \\
\hline 2007 & 49 & -14 & -26 & -40 & 9 & 42 & 42 & 37 & -4 & -36 & -49 & -9 \\
\hline 2008 & 51 & 3 & -33 & -45 & -25 & 78 & 68 & 60 & -40 & -70 & -54 & 5 \\
\hline 2009 & 45 & 45 & -35 & -44 & 12 & 46 & 53 & 39 & -10 & -62 & -54 & -32 \\
\hline 2010 & 19 & 67 & 22 & -3 & -5 & 2 & 20 & 31 & -4 & -64 & -61 & -23 \\
\hline 2011 & 24 & 38 & -6 & 50 & 76 & -12 & -16 & -1 & -26 & -60 & -41 & -27 \\
\hline 2012 & 33 & 30 & 3 & -8 & 40 & 39 & 0 & 20 & -29 & -71 & -57 & -2 \\
\hline
\end{tabular}

Fonte: SISTEMA DE INFORMAÇÃO E ESTATÍSTICA DE MERCADO, 2013.

TABELA 22- Sazonalidade de valor da carambola comercializada na CEAGESP, de 2007 a 2012.

\begin{tabular}{|l|c|c|c|c|c|c|c|c|c|c|c|c|}
\hline Ano & Jan. & Fev. & Mar. & Abr. & Maio & Jun. & Jul. & Ago. & Set. & Out. & Nov. & Dez. \\
\hline 2007 & 9 & -20 & -20 & 6 & -11 & -24 & -20 & -23 & -10 & 14 & 49 & 49 \\
\hline 2008 & -7 & -12 & -11 & -2 & -5 & -27 & -29 & -11 & 18 & 63 & 31 & -10 \\
\hline 2009 & -3 & -15 & -10 & -20 & -21 & -24 & -0 & 18 & 25 & 15 & 22 & 13 \\
\hline 2010 & 0 & -13 & -17 & -16 & -18 & -27 & -17 & -12 & 1 & 25 & 80 & 13 \\
\hline 2011 & -7 & -10 & -11 & -7 & -24 & -10 & 4 & 11 & 4 & 46 & 11 & -7 \\
\hline 2012 & -20 & -30 & -16 & -7 & -14 & -18 & -11 & 1 & 14 & 50 & 61 & -12 \\
\hline
\end{tabular}

Fonte: SISTEMA DE INFORMAÇÃO E ESTATÍSTICA DE MERCADO, 2013.

TABELA 23- Evolução do volume em kg de abiu comercializado na CEAGESP, de 2007 a 2012.

\begin{tabular}{|l|c|c|c|c|c|c|}
\hline \multicolumn{1}{|c|}{ Mês } & $\mathbf{2 0 0 7}$ & $\mathbf{2 0 0 8}$ & $\mathbf{2 0 0 9}$ & $\mathbf{2 0 1 0}$ & $\mathbf{2 0 1 1}$ & $\mathbf{2 0 1 2}$ \\
\hline Volume kg & Volume kg & Volume kg & Volume kg & Volume kg & Volume kg \\
\hline Fevereiro & 1.939 & 738 & 1.406 & 732 & 3.960 & 1.868 \\
\hline Março & 2.907 & 1.990 & 1.472 & 828 & 2.452 & 1.324 \\
\hline Abril & 606 & 1.996 & 3.808 & 2.920 & 4.584 & 2.180 \\
\hline Maio & 110 & 1.016 & 504 & 3.444 & 780 & 1.634 \\
\hline Junho & 360 & 162 & 96 & 1.110 & 2.068 & 306 \\
\hline Julho & 1.908 & 826 & 726 & 2.026 & 2.752 & 1.984 \\
\hline Agosto & 5.180 & 2.374 & 3.824 & 460 & 338 & 1.922 \\
\hline Setembro & 4.130 & 3.258 & 2.288 & 914 & 2.118 & 714 \\
\hline Outubro & 3.860 & 2.132 & 1.658 & 1.388 & 454 & 616 \\
\hline Novembro & 2.086 & 40 & 1.196 & 766 & 20 & 56 \\
\hline Dezembro & 394 & 86 & 474 & - & 216 & 14 \\
\hline Total & 24.267 & 15.688 & 21.866 & 18.980 & 20.866 & 14.132 \\
\hline
\end{tabular}

Fonte: SISTEMA DE INFORMAÇÃO E ESTATÍSTICA DE MERCADO, 2013. 
TABELA 24- Sazonalidade do volume do abiu comercializado na CEAGESP, de 2007 a 2012.

\begin{tabular}{|l|c|c|c|c|c|c|c|c|c|c|c|c|}
\hline Ano & Jan. & Fev. & Mar. & Abr. & Maio & Jun. & Jul. & Ago. & Set. & Out. & Nov. & Dez. \\
\hline $\mathbf{2 0 0 7}$ & -4 & -61 & 44 & -70 & -95 & -82 & -6 & 156 & 104 & 91 & 3 & -81 \\
\hline $\mathbf{2 0 0 8}$ & -44 & -17 & 51 & 53 & -22 & -88 & -37 & 82 & 149 & 63 & -97 & -93 \\
\hline $\mathbf{2 0 0 9}$ & -23 & -19 & 142 & 109 & -72 & -95 & -60 & 110 & 26 & -9 & -34 & -74 \\
\hline $\mathbf{2 0 1 0}$ & -54 & -48 & 178 & 85 & 118 & -30 & 28 & -71 & -42 & -12 & -52 & -100 \\
\hline $\mathbf{2 0 1 1}$ & 128 & 41 & -35 & 164 & -55 & 19 & 58 & -81 & 22 & -74 & -99 & -88 \\
\hline $\mathbf{2 0 1 2}$ & 59 & 12 & 29 & 85 & 39 & -74 & 68 & 63 & -39 & -48 & -95 & -99 \\
\hline
\end{tabular}

Fonte: SISTEMA DE INFORMAÇÃO E ESTATÍSTICA DE MERCADO, 2013.

TABELA 25-Evolução do volume do umbu comercializado na CEAGESP, de 2007 a 2012

\begin{tabular}{|l|c|c|c|c|c|c|}
\hline & $\mathbf{2 0 0 7}$ & $\mathbf{2 0 0 8}$ & $\mathbf{2 0 0 9}$ & $\mathbf{2 0 1 0}$ & $\mathbf{2 0 1 1}$ & $\mathbf{2 0 1 2}$ \\
\hline Mês & Volume kg & Volume kg & Volume kg & Volume kg & Volume kg & Volume kg \\
\hline Janeiro & 38.994 & 38.394 & 7.350 & 8.714 & 13.554 & 23.760 \\
\hline Fevereiro & 0 & 31.210 & 169.016 & 13.220 & 3.184 & 330 \\
\hline Março & 0 & 28 & 450 & 288 & 440 & 154 \\
\hline Abril & 650 & 632 & 226 & 548 & 804 & 1.208 \\
\hline Maio & 694 & 360 & 748 & 1.178 & 2.392 & 2.498 \\
\hline Junho & 3.316 & 1.194 & 514 & 3.018 & 938 & 1.652 \\
\hline Julho & 2.278 & 1.148 & 2.290 & 1.186 & 1.958 & 2.378 \\
\hline Agosto & 1.054 & 804 & 5.202 & 1.418 & 2.528 & 3.466 \\
\hline Setembro & 74 & 932 & 976 & 258 & 244 & 152 \\
\hline Outubro & 0 & 60 & 0 & 0 & 0 & 0 \\
\hline Novembro & 314 & 7.500 & 0 & 0 & 0 & 0 \\
\hline Dezembro & 21.530 & 32.320 & 1.766 & 22.700 & 21.400 & 260 \\
\hline Total & 68.904 & 114.582 & 188.538 & 52.528 & 47.442 & 35.858 \\
\hline
\end{tabular}

Fonte: SISTEMA DE INFORMAÇÃO E ESTATÍSTICA DE MERCADO, 2013.

TABELA 26- Sazonalidade do volume do umbu comercializado na CEAGESP, de 2007 a 2012.

\begin{tabular}{|c|c|c|c|c|c|c|c|c|c|c|c|c|}
\hline Ano & Jan. & Fev. & Mar. & Abr. & Maio & Jun. & Jul. & Ago. & Set. & Out. & Nov. & Dez. \\
\hline $\mathbf{2 0 0 7}$ & 579 & -100 & -100 & -89 & -88 & -42 & -60 & -82 & -99 & -100 & -95 & 275 \\
\hline $\mathbf{2 0 0 8}$ & 302 & 227 & -100 & -93 & -96 & -87 & -88 & -92 & -90 & -99 & -21 & 238 \\
\hline $\mathbf{2 0 0 9}$ & -53 & 976 & -97 & -99 & -95 & -97 & -85 & -67 & -94 & -100 & -100 & -89 \\
\hline $\mathbf{2 0 1 0}$ & 99 & 202 & -93 & -87 & -73 & -31 & -73 & -68 & -94 & -100 & -100 & 419 \\
\hline $\mathbf{2 0 1 1}$ & 243 & -19 & -89 & -80 & -39 & -76 & -50 & -36 & -94 & -100 & -100 & 441 \\
\hline $\mathbf{2 0 1 2}$ & 695 & -89 & -95 & -60 & -16 & -45 & -20 & 16 & -95 & -100 & -100 & -91 \\
\hline
\end{tabular}

Fonte: SISTEMA DE INFORMAÇÃO E ESTATÍSTICA DE MERCADO, 2013. 


\section{CONCLUSÃO}

1-Apesar do aumento significativo da demanda das frutas exóticas nos últimos anos, o volume total ainda é pequeno em relação ao volume total das demais frutas, e apesar de ser um nicho de mercado, a tendência é de crescimento.

2-A oferta de algumas variedades de frutas exóticas nos principais CEASAs, em especial do mercado da CEAGESP, teve crescimento surpreendente em razão do excelente sabor, como foi o caso da lichia, do mangostão e das frutas vermelhas- amora e framboesa.

3-Em algumas frutas, a demanda está relacionada ao saudosismo dos consumidores com sua origem, como é o caso dos nordestinos com o umbu e abiu.

\section{REFERÊNCIAS}

CONAB - Companhia Nacional de Abastecimento. Programa brasileiro de modernização do mercado hortigranjeiro. Disponível em: $<$ http://dw.prohort. conab.gov.br/pentaho/Prohort $>$. Acesso em: $20 \mathrm{fev}$. 2013.

SIEM - Sistema de Informação e Estatística de Mercado da Companhia de Entrepostos e Armazéns Gerais de São Paulo. São Paulo: CEAGESP, Seção de Economia e Desenvolvimento, 2013. Não publicado. 